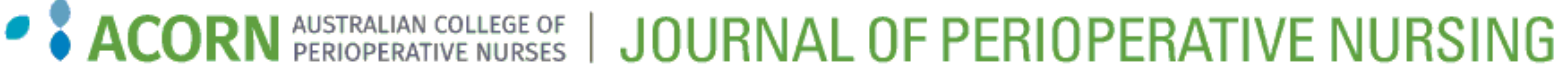

\title{
Task transfer: A survey of Australian surgeons on the role of the non-medical surgical assistant
}

Follow this and additional works at: https://www.journal.acorn.org.au/jpn

Part of the Health Services Administration Commons, Health Services Research Commons, Perioperative, Operating Room and Surgical Nursing Commons, and the Surgery Commons

(c) (1)

This work is licensed under a Creative Commons Attribution 4.0 License.

\section{Recommended Citation}

Hains, Toni; Turner, Catherine; and Strand, Haakan (2018) "Task transfer: A survey of Australian surgeons on the role of the non-medical surgical assistant," Journal of Perioperative Nursing: Vol. 31 : Iss. 1 , Article 1.

Available at: https://doi.org/10.26550/2209-1092.1020

https://www.journal.acorn.org.au/jpn/vol31/iss1/1

This Article is brought to you for free and open access by Journal of Perioperative Nursing. It has been accepted for inclusion in Journal of Perioperative Nursing by an authorized editor of Journal of Perioperative Nursing. 


\section{Authors}

\section{Toni Hains}

MClinSc (PNSA), MNPractSt, RN

The University of Queensland, School of Nursing, Midwifery and Social Work

\section{Catherine Turner}

PhD, RN

Professor of Nursing, The University of Queensland, School of Nursing, Midwifery and Social Work

\section{Haakan Strand}

PhD, MNPractSt, RN

Program Director - Master of Nurse Practitioner Studies, The University of Queensland, School of Nursing, Midwifery and Social Work

\section{Corresponding author}

Toni Hains

School of Nursing, Midwifery and Social Work

Level 3, Chamberlain Building,

The University of Queensland

St Lucia, QLD 4072

E: s4277231@student.uq.edu.au

\title{
Task transfer: A survey of Australian surgeons on the role of the non-medical surgical assistant
}

\begin{abstract}
Background: A non-medical surgical assistant is a clinician who provides perioperative care in the role of surgical assistant but does not possess a medical degree. This role has been practiced in Australia for more than 20 years.
\end{abstract}

Aim: This survey investigates Australian surgeons' attitudes and current practice regarding the role of the non-medical surgical assistant.

Design/method: Distribution of the survey was online in December 2015 by the Royal Australasian College of Surgeons (RACS). Data analysis was descriptive using online survey methodology and convenience sampling.

Results: In the private sector in Australia 105 respondents (35 per cent) use a non-medical surgical assistant. In the private sector in Australia, 188 respondents (64 per cent) were 'very supportive' or 'supportive to some degree' of the role, with 60 (20 per cent) 'undecided' and 48 (16 per cent) 'not supportive'.

Conclusion: The results illustrate there is support in the Australian surgical community for the role. The majority of respondents advocated contribution to governance of the role and curricula oversight by the RACS.

Keywords: non-medical surgical assistant, perioperative nurse surgeon's assistant, perioperative nurse practitioner, Royal Australasian College of Surgeons

\section{Introduction}

The lines of demarcation between health care professionals were once clear. Gender, education and the ability to prescribe have historically differentiated doctors and nurses?. Privileges of medical practice protected by legislation and insurance reimbursement are no longer the sole domain of the medical doctor ${ }^{2}$. A need for 'non-physician practitioners' to meet changes in the health care environment has contributed to less defined lines of demarcation between health care professionals' roles $^{3-6}$. In the light of alterations to the context of health care and availability of resources, registered nurses (RNs) and allied health professionals are acknowledged as an under-used asset for safe and cost effective health care delivery ${ }^{7-10}$. Task transfer does not dilute medical care but does strengthen health care $^{11}$.

\section{Background}

The role of the non-medical surgical assistant (NMSA) is well established in the international setting with clinicians who are not medical doctors providing perioperative care $^{12}$. An example of international support for the NMSA role is well illustrated in the United Kingdom (UK). The Royal College of Surgeons England (RCSE) has been proactive 
in undertaking a comprehensive review of the curriculum of the NMSA $^{13}$. The objective was to improve performance of the entire surgical team. This work culminated with the updated curriculum framework for the surgical care practitioner (SCP) in $2014^{14}$. The RCSE also requested streamlining of titles of NMSA within the UK to standardise parameters for the roles ${ }^{13,15}$.

By comparison, the Royal Australasian College of Surgeons (RACS) has had little input into curriculum or training of the NMSA in Australia. The most recent position statement (2015) from the RACS on the surgical assistant does not outline what specific qualifications a surgical assistant should hold and suggests the level of knowledge and skill is at the discretion of the surgeon $^{16}$. This is in contrast to the Medicare Benefits Scheme which will only remunerate doctors for intraoperative 'assisting at operation' in the private sector ${ }^{17}$.

The majority of clinicians performing this role in Australia are RNs ${ }^{18}$. The nursing labels in Australia for NMSAs are perioperative nurse surgeon's assistant (PNSA) or nurse practitioner $(N P)^{19,20}$.

At the inception of the NMSA role in Australia in 1999, the RACS president indicated that the RACS would support an intraoperative component of the role ${ }^{21}$. There is a paucity of evidence of early RACS support in the Australian literature. A surgical workforce census report in 2011 outlined that RACS members were supportive of the roles of NP and physician assistant (PA) as surgical assistants $^{22}$. A 2006 paper by RACS members on the topic of the NMSA highlighted recruitment, training and supervision of the NMSA as potential issues. The emphasis of this paper was that evolution of roles should be within a framework of 'defined knowledge and competencies' based in evidence, supporting a high level of care and patient safety ${ }^{23}$.

Historically many advanced practice roles have been to meet a clinical need without the accompanying statutory direction and governance ${ }^{20,24-26}$. What is prominent in the literature about advance practice nursing roles is the need for regulated, standardised education and accompanying suitable clinical proficiencies 6 6,13,27-32.

\section{Aim}

The survey aimed to clarify:

1. surgeons' opinions

- Do surgeons support the role in Australia?

- Which qualifications were appropriate?

- What governance structure was required?

- What input should the RACS have in curriculum development and training?

\section{2. surgeons' practice}

- Quantify the experience of surgeons.

- Determine who in Australia was using NMSAs.

\section{Participants/ethics}

The survey had ethics approval from The University of Queensland (\#2015000084).

While this paper refers to Australian surgeons, RACS' membership also includes New Zealand (NZ) surgeons, who constituted only 1 per cent of respondents. Surgeons, both active and retired, and trainees were eligible for the survey.

\section{Survey/sampling}

The survey was advertised as per RACS's policy for 'external' surveys via

their online newsletter, Fax mentis, in December 2015 and January 2016. Due to a low response rate, second round contact was established with individual surgical specialty associations and societies. Once the survey was distributed beyond the affiliation with the RACS, membership of the RACS was not necessary to participate.

When specialty surgical groups were approached, how they chose to circulate the survey to members influenced how many members responded. Some specialty groups such as General Surgeons Australia and the Australia and New Zealand Society of Vascular Surgeons emailed the survey link directly to members; the Australian Orthopaedic Association Limited (AOA) placed a link to the survey on their website. For this reason specialty response rates were not reflective of the membership of these surgical specialty organisations. Low response does expose the survey to non-responder bias ${ }^{33}$.

In a recent practice audit of the NMSA role in Australia, the surgical specialty with the highest uptake of NMSA use was orthopaedic surgery, followed by general surgery and then gynaecology ${ }^{18}$. Gynaecologists and obstetricians were not well represented in the membership of the RACS and the Royal Australian and New Zealand College of Obstetricians and Gynaecologists declined the request to circulate the survey to members.

\section{Data analysis}

Collected data were predominately of quantitative character. Descriptive data analysis was undertaken within Qualtrics (Qualtrics, Provo, UT) software ${ }^{34}$. 
Table 1: Demographic data of participants

\begin{tabular}{|l|r|}
\hline Age (years) & $n=343(\%)$ \\
\hline 30 or younger & $4(1)$ \\
\hline $31-40$ & $77(23)$ \\
\hline $41-50$ & $105(31)$ \\
\hline $51-60$ & $83(24)$ \\
\hline $61-70$ & $56(16)$ \\
\hline $71-80$ & $12(3)$ \\
\hline 81 or older & $6(2)$ \\
\hline
\end{tabular}

\begin{tabular}{|l|r|}
\hline Gender & $\mathrm{n}=344(\%)$ \\
\hline Male & $284(83)$ \\
\hline Female & $60(17)$ \\
\hline
\end{tabular}

\begin{tabular}{|l|r|}
\hline $\begin{array}{l}\text { Experience as a } \\
\text { consultant (years) }\end{array}$ & $\mathrm{n}=335(\%)$ \\
\hline Trainee & $17(5)$ \\
\hline 5 or less & $70(21)$ \\
\hline $6-10$ & $45(13)$ \\
\hline $11-15$ & $46(14)$ \\
\hline $16-20$ & $38(11)$ \\
\hline $21-25$ & $35(10)$ \\
\hline $26-30$ & $27(8)$ \\
\hline $31-35$ & $29(9)$ \\
\hline 36 or more & $28(8)$ \\
\hline
\end{tabular}

\begin{tabular}{|c|c|c|}
\hline \multicolumn{2}{|c|}{$\begin{array}{l}\text { Practicing status } \\
\text { and state/territory/ } \\
\text { country if practicing* }\end{array}$} & $\mathrm{n}=337(\%)$ \\
\hline \multirow{9}{*}{ 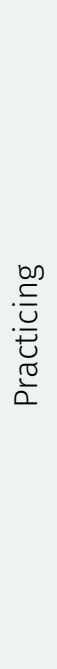 } & Victoria & $79(23)$ \\
\hline & New South Wales & $97(29)$ \\
\hline & Queensland & $103(31)$ \\
\hline & $\begin{array}{l}\text { Northern } \\
\text { Territory }\end{array}$ & $5(1)$ \\
\hline & Western Australia & $28(8)$ \\
\hline & South Australia & $35(10)$ \\
\hline & Tasmania & $10(3)$ \\
\hline & $\begin{array}{l}\text { Australian Capital } \\
\text { Territory }\end{array}$ & $4(1)$ \\
\hline & New Zealand & $4(1)$ \\
\hline \multicolumn{2}{|c|}{ Retired } & $6(2)$ \\
\hline \multicolumn{2}{|c|}{$\begin{array}{l}\text { Not currently } \\
\text { practicing (other than } \\
\text { retirement) }\end{array}$} & $2(1)$ \\
\hline
\end{tabular}

\begin{tabular}{|l|c|}
\hline Region of practice* & $\mathrm{n}=336(\%)$ \\
\hline Metropolitan & $227(68)$ \\
\hline Regional & $117(35)$ \\
\hline Rural & $27(8)$ \\
\hline
\end{tabular}

\section{* Participants may practice in more than one state or region}

\section{Results}

In total 445 surveys were submitted, however, not all respondents answered all of the questions. The majority of respondents (227 or 68 per cent) practiced in the metropolitan area and the largest number of respondents were from Queensland (103 or 31 per cent). Demographics of respondents are presented in Table 1.

General surgery was the most common specialty with 187 (56 per cent) respondents. This influenced the highest uptake of NMSA in general surgery (see Table 2, on the next page). In regard to support of the role of the NMSA in the private sector in Australia, 188 respondents (69 per cent) were 'very supportive' or 'supportive to some degree', with 60 (22 per cent) 'undecided' and 48 (16 per cent) were 'not supportive'. Surgeons were less supportive of the NMSA in the public sector (refer Figure 1). Of the 334 responses 125 (38 per cent) had no experience working with an NMSA, while 116 (35 per cent) had experience with an NMSA in Australia. When amount of experience working with an NMSA and level of support of the NMSA were cross-tabulated, surgeons with 'No experience' working with an NMSA constituted the highest tally for "not supportive' or 'undecided'.

Regarding qualifications, as outlined in Table 3 on page 17, 175 surgeons (53 per cent) thought a registered nurse (RN) with any postgraduate surgical assisting qualification was sufficient to work in the role. Looking at both extremes of the nursing qualification spectrum, 50 surgeons (15 per cent) thought an enrolled nurse qualification was sufficient while 119 (36 per cent) thought an NP qualification was appropriate. Other qualifications considered appropriate were physician assistant (PA) (105 or 32 per cent) or any allied health degree (34 or 10 per cent) with 79 (24 per cent) asserting that only a medical degree was acceptable.

As outlined in Table 4 (see page 18), surgeons were equally divided on whether the Nursing and Midwifery Board of Australia (NMBA) or the Medical Board of Australia (MBA) should govern the role of the NMSA. Regarding the RACS, 139 (43 per cent) thought the RACS should contribute to governance, 42 (13 per cent) thought the RACS should have sole responsibility for curriculum development whereas 180 (56 per cent) thought the RACS should have input into curriculum development.

Current practice reflects 105 respondents (35 per cent) currently used an NMSA in the private sector and 30 (9 per cent) used an NMSA in the public sector. A number of respondents 16 (5 per cent) used an NMSA to operate on public patients in the private sector. 
Figure 1: Surgeon support for NMSA role in public and private sectors

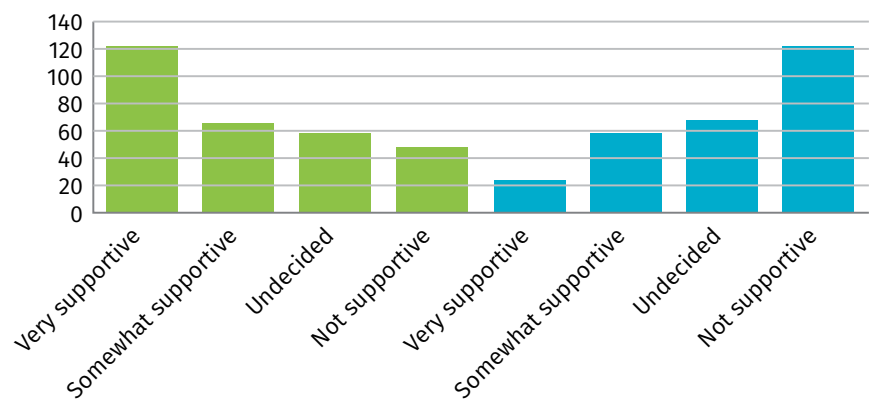

Private sector

Public sector

Table 2: Utilisation of an NMSA in Australia via surgical specialty

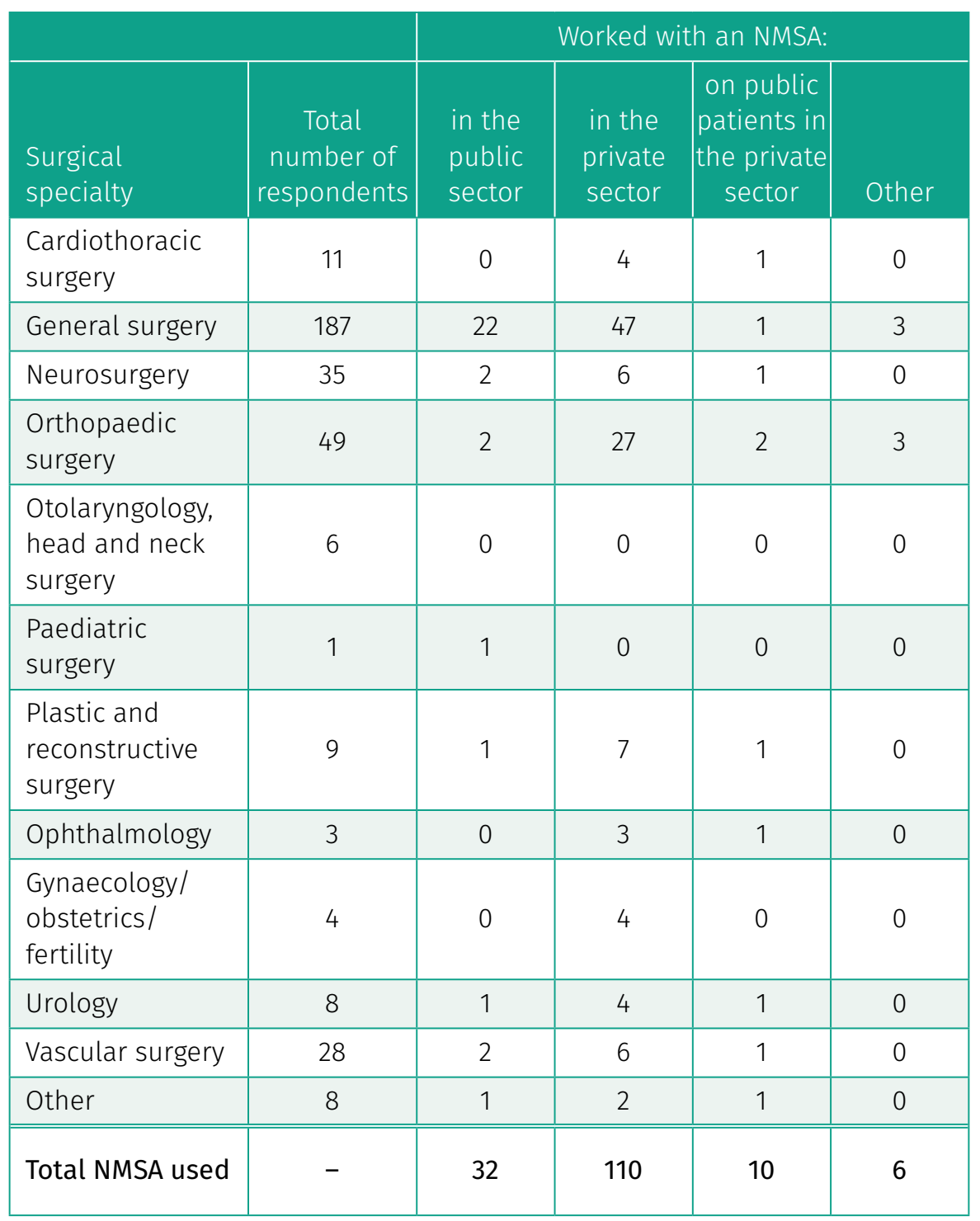

\section{Discussion}

Scrutinising the trends of support between the public and private sectors, a similar number of surgeons were 'very supportive' of the NMSA in the private sector as 'not supportive' in the public sector. This may be attributed to a concern that the NMSA will negatively impact junior doctor training; however, this is not supported in the literature ${ }^{20,28,35-37}$. Regarding current practice, nine of the 16 surgeons who operate on public patients in the private sector were from Queensland, most likely due to a contract between the state and a corporate health care provider to address public surgical waiting lists. The NMSA proved an economical alternative to medical assistants for this contract ${ }^{38}$.

There was support amongst respondents for a wide range of qualifications to perform the role of the NMSA. In this survey 36 per cent of respondents thought an NP qualification was appropriate and 32 per cent thought a PA was appropriate. This percentage of support is less than reported in a surgical workforce census report published by the RACS in $2011^{22}$. In this report 48.6 per cent of surgeons supported the role of NP (nursing model) as surgical assistant and 46.3 per cent supported the role of PA (medical model) as a surgical assistant ${ }^{39,40}$.

While 47 respondents (15 per cent) thought the RACS should have no input into the initial and ongoing education of the role of the NMSA in Australia, the paper published by the RACS representatives in 2006 states the RACS would support new health care roles in surgery if an appropriate curriculum and standards are developed ${ }^{23}$. For proper curriculum and standards development it would be ideal to have surgeon input. This view is supported by 
Table 3: Qualifications of NMSAs that Australian surgeons have worked with and qualifications that Australian surgeons considered appropriate for the role of NMSA

\begin{tabular}{|l|r|}
\hline $\begin{array}{l}\text { Qualifications of NMSAs that Australian surgeons have } \\
\text { worked with* }\end{array}$ & $\mathrm{n}=332(\%)$ \\
\hline Enrolled Nurse & $24(7)$ \\
\hline Registered Nurse & $160(48)$ \\
\hline Nurse Practitioner & $39(12)$ \\
\hline Physician Assistant & $18(5)$ \\
\hline Allied Health Professional & $2(1)$ \\
\hline I have not worked with an NMSA in Australia & $146(44)$ \\
\hline Other & $8(2)$ \\
\hline I don't know the qualification of the NMSA & $6(2)$ \\
\hline
\end{tabular}

\begin{tabular}{|l|r|}
\hline $\begin{array}{l}\text { Qualifications that Australian surgeons considered } \\
\text { appropriate for the role of NMSA* }\end{array}$ & $\mathrm{n}=328(\%)$ \\
\hline Enrolled Nurse & $50(15)$ \\
\hline Registered Nurse (RN) & $109(33)$ \\
\hline RN with any postgraduate surgical assisting qualification & $175(53)$ \\
\hline $\begin{array}{l}\text { RN with a master's postgraduate surgical assisting } \\
\text { qualification }\end{array}$ & $108(33)$ \\
\hline Nurse Practitioner & $119(36)$ \\
\hline Physician Assistant & $105(32)$ \\
\hline Allied Health Professional & $34(11)$ \\
\hline $\begin{array}{l}\text { Only clinicians with a medical degree should be a } \\
\text { surgical assistant }\end{array}$ & $79(24)$ \\
\hline Other & $8(2)$ \\
\hline
\end{tabular}

* Participants were able to select more than one option

222 respondents (69 per cent) who selected 'sole responsibility for curriculum development' or 'input into curriculum development' as their answer to this question.

\section{Conclusion}

Survey results are highly dependent on the circulation process. To obtain more thorough results a RACS internal survey emailed directly to members would be the ideal method.
The results presented here, skewed by the mode of distribution, show that there is support in the surgical community for the role of the NMSA in Australia. Results indicate that the RACS should be involved in governance and curriculum development of the role of the NMSA in Australia.

It is anticipated this paper will provide stimulus for discussion within the RACS on the role of the NMSA in Australia. Similar to the RCSE, RACS and the wider Australian surgical community has the opportunity to support and guide development of the role of the NMSA in Australia. As stated by Dr Van Der Weyden, past editor of the Medical Journal of Australia, knowing when to delegate professional responsibilities is not a task for the individual practitioner, but for the profession ${ }^{41}$.

\section{Limitations}

Low response rate due to the RACS's policy regarding circulation of 'external' surveys was problematic. The optimal sample size of 368 was reached by circulation outside the discrete RACS population.

\section{Postscript}

During the process of this manuscript being reviewed and published the Royal Australasian College of Surgeons wrote a letter to the Australian Association of Nurse Surgical Assistants. The letter outlines support for the role of the Perioperative Nurse Surgeon's Assistant and highlights the need for standardised education and formal credentialing of the role.

There was no financial assistance for this project.

\section{References}

1. Romano CA. What is a doctor and what is a nurse? A perspective for future practice and education. Acad Med 2014;89(7):970-972.

2. Ten Cate $\mathrm{O}$. What is a $21^{\mathrm{st}}$-century doctor? Rethinking the significance of the medical degree. Acad Med 2014;89(7):966-969.

3. Simborg DW, Starfield BH, Horn SD. Physicians and non-physician health practitioners: The characteristics of their practices and their relationships. Am J Public Health 1978;68(1):44-48.

4. Berger J, D'Cunha J. Measuring what we value: Quantifying the impact of the physician extender in surgical care. Semin Thorac Cardiovasc Surg 2012;24(2):85-86.. 
Table 4: Australian surgeons' opinions on the role of the Royal Australasian College of Surgeons (RACS) in NMSA education and who should govern the NMSA role

\begin{tabular}{|l|r|}
\hline RACS's role in NMSA education* & $\mathrm{n}=324(\%)$ \\
\hline Sole responsibility for curriculum development & $42(13)$ \\
\hline Input into curriculum development & $180(56)$ \\
\hline Mentor NMSA students assisting qualification & $136(42)$ \\
\hline Conduct lectures or practical skills sessions & $157(48)$ \\
\hline Initial and ongoing credentialing of NMSAs in hospitals & $151(47)$ \\
\hline Develop standard, policy and position statement for the NMSA & $6(2)$ \\
\hline Other & $47(15)$ \\
\hline I don't think the RACS should have input & \\
\hline
\end{tabular}

\begin{tabular}{|l|r|}
\hline Who should govern the NMSA role* & \\
\hline $\begin{array}{l}\text { Australian Health Professional Regulation Agency (AHPRA) via } \\
\text { the Nursing and Midwifery Board of Australia }\end{array}$ & $140(43)$ \\
\hline AHPRA via the Medical Board of Australia & $133(41)$ \\
\hline Royal Australasian College of Surgeons & $139(43)$ \\
\hline Other medical associations e.g. surgical specialty groups & $23(7)$ \\
\hline Australian College of Nursing & $50(15)$ \\
\hline Australian College of Nurse Practitioners & $64(20)$ \\
\hline Other professional nursing associations e.g. ACORN & $72(22)$ \\
\hline Hospital executive via credentialing process & $127(39)$ \\
\hline Other & $7(2)$ \\
\hline I don't support the role of the NMSA & $62(19)$ \\
\hline
\end{tabular}

* Participants were able to select more than one option

5. Van Der Weyden M. Task transfer: Another pressure for evolution of the medical profession. Med J Aust 2006;185(1):29-31.

6. Mikhail J, Millerz W, Wagner J. Midlevel practitioner role evolution in an American College of Surgeons-verified trauma surgery service: The 23-year experience at Hurley Medical Center. J Trauma Nurs 2009;16(1):3340.

7. William G, Crilly J, Souter J, Veach K, Good N. A state wide validation and utilisation study of the Queensland emergency nursing workforce tool. J Nurs Manag 2014;22:10761088.

8. Abraham J. Innovative perioperative role improves patient and organisational outcomes in minimally invasive surgery. I Perioper Pract 2011;21(5):158-164.
14. Royal College of Surgeons England (RCS). Surgical care practitioner curriculum 2014 [Internet] London: RCS 2014 [cited 2015 November 23]. Available from: www.rcseng. ac.uk/surgeons/training/accreditation/ surgical-care-practitioners-scps.

15. Perioperative Care Collaborative (PCC). Position statement: Surgical first assistant 2012 [Internet]. London: PCC; 2012 [cited 2015 January 2]. Available from: www.afpp.org.uk/ careers/Standards-Guidance.

16. Royal Australasian College of Surgeons (RACS). Position statement - Surgical assistants. Melbourne: RACS; 2015 [cited 2015 May 1]. Available from: www.surgeons.org/ media/304233/2015-05-20_pos_fes-pst-028 surgical_assistants.pdf

17. Victorian Government. 10.5.22.6 The MBS rules 2014 [Internet]. Melbourne: Victorian Government; 2014. Available from: www1.worksafe.vic.gov.au/vwa/ claimsmanual/Content/10Entitlements MedicalAndLikeServices/1\%205\%2022\%20 6\%20The\%20MBS\%20rules.htm.

18. Hains T, Turner C, Strand H. Practice audit of the role of the non-medical surgical assistant in Australia, an online survey. Int J Nurs Pract 2016;22(6):546-555.

19. Bryant E. Perioperative nurse surgeon's assistants in day surgery an emerging role within Australia's health system. Ambul Surg 2010 6(2):25-27.

20. Hamlin L, Dobson J, Cook L. Perioperative nurse practitioners (NP) - The first two perioperative NPS are authorised in NSW. ACORN 2010;23(4):6-10.

21. Brennan B. The registered nurse as a first assistant: The 'downunder' experience. Semin Perioper Nurs 2001;10(2):108-114

22. Royal Australasian College of Surgeons. Surgical workforce census summary report. Melbourne: RACS; 2011. Available from: www.surgeons.org.

23. Collins J, Hillis D, Stitz R. Task transfer: The view of the Royal Australasian College of Surgeons. Med J Aust 2006;185(1):25-26.

24. Lloyd-Jones M. Role development and effective practice in specialist and advanced practice roles in acute hospital settings: Systematic review and meta-synthesis. J Adv Nurs 2005;49(2):191-209.

25. Yang L, Hains T. The plight of the perioperative nurse practitioner. Aust Nurs Midwifery I 2017;24(10):36-37.

26. Hains T, Turner $C$, Strand $H$. Knowledge and perceptions of the non-medical surgical assistant role in Australia - A perioperative staff survey. ACORN 2017;30(3):39-43, 45.

27. Quick J. The role of the surgical care practitioner within the surgical team. $\mathrm{Br}$ J Nurs 2013;22(13):759-765. 
28. Quick J, Hall S, Jones A. The surgical care practitioner role problems and possible solutions from nurses in the UK offered to RNFSA colleagues in New Zealand. Dissector. 2014;42(1):32-34

29. Currie J, Edwards L, Colliban M, Crouch R. A time for international standards?: Comparing the emergency nurse practitioner role in the UK, Australia and New Zealand. Accid Emerg Nurs 2007;159(4):210-216.

30. Al-Hashami J. The role of the advanced scrub practitioner. J Perioper Pract 2007;17(2):76-80.

31. Battie R, Steelman V. Accountability in nursing practice: Why it is important for patient safety. ACORN 2015;28(4):14.
32. Hains T, Turner C, Gao Y, Strand H. Valuing the role of the non-medical surgical assistant. Aust NZ J Surg 2017;87(4):222-223.

33. Vangeest JB, Johnson TP. Surveying clinicians: An introduction to the special issue. Eval Health Prof 2013;36(3):275-278.

34. Polit DF, Beck CT. Nursing research: Generating and assessing evidence for nursing practice. Philadelphia: Wolters Kluwer Health / Lippincott Williams \& Wilkins; 2012.

35. Jones A, Arshad H, Nolan J. Surgical care practitioner practice: One team's journey explored. J Perioper Pract 2012;22(1):19-23.

36. Alex J, Rao V, Cale A, Griffin S, Cowen M, Guvendik L. Surgical nurse assistants in cardiac surgery: A UK trainee's perspective. Eur J Cardiothorac Surg 2004;25(1):111-115.
37. Aning J. Surgical care practitioners are having a detrimental effect on surgical training [Internet]. London: British Medical Journal Careers; 2006.

38. Smith C, Hains T, Mannion N. An opportunity taken: Sunshine Coast University Private Hospital's perioperative nurse surgical assistant experience. ACORN 2016;29(3):2328.

39. Hass V. Physician assistants and nurse practitioners are not interchangeable. JAAPA 2016;29(4):9-12.

40. Hains T, Turner C, Strand H. The non-medical surgical assistant in Australia - Who should contribute to governance? Aust J Adv Nurs 2017;35(2):In Press.

41. Van Der Weyden MB. Debating health workforce innovation. Med J Aust 2006;184(3):100-101. 